\title{
Using smartphones to document linguistic landscapes: The LinguaSnapp mobile app
}

DOI:

10.1515/lingvan-2019-0012

\section{Document Version}

Final published version

Link to publication record in Manchester Research Explorer

\section{Citation for published version (APA):}

Matras, Y., \& Gaiser, L. (2021). Using smartphones to document linguistic landscapes: The LinguaSnapp mobile app. Linguistics Vanguard, 7(s1), 1-18. [20190012]. https://doi.org/10.1515/lingvan-2019-0012

\section{Published in:}

Linguistics Vanguard

\section{Citing this paper}

Please note that where the full-text provided on Manchester Research Explorer is the Author Accepted Manuscript or Proof version this may differ from the final Published version. If citing, it is advised that you check and use the publisher's definitive version.

\section{General rights}

Copyright and moral rights for the publications made accessible in the Research Explorer are retained by the authors and/or other copyright owners and it is a condition of accessing publications that users recognise and abide by the legal requirements associated with these rights.

\section{Takedown policy}

If you believe that this document breaches copyright please refer to the University of Manchester's Takedown Procedures [http://man.ac.uk/04Y6Bo] or contact uml.scholarlycommunications@manchester.ac.uk providing relevant details, so we can investigate your claim.

\section{OPEN ACCESS}




\title{
Leonie Elisa Gaiser* and Yaron Matras
}

\section{Using smartphones to document linguistic landscapes: the LinguaSnapp mobile app}

https://doi.org/10.1515/lingvan-2019-0012

Received February 7, 2019; accepted January 14, 2020

\begin{abstract}
LinguaSnapp is a smartphone application developed to support documentation of linguistic landscapes, especially in multilingual urban settings. Since its launch in Manchester in 2016, bespoke versions have also been created for Melbourne, Jerusalem, St Petersburg and Hamburg. We describe the rationale and the operational setup behind the app, and provide examples of how the documentation facility can support analyses pertaining to the relation between language repertoire and spatial demarcations, and how it can be used in public engagement.
\end{abstract}

Keywords: multilingualism; linguistic landscape; internationalisation; public engagement

\section{Introduction}

This paper introduces the smartphone application LinguaSnapp, an innovative tool for documenting and analysing linguistic landscapes. The study of linguistic landscapes (LL) - language use on street signs, commercial signs, posters or other texts in the public space - has attracted increasing cross-disciplinary interest. LL research has developed from an early focus on counting and documenting written languages and scripts (e.g. Rosenbaum et al. 1977; Wenzel 1996; Landry and Bourhis 1997; Backhaus 2007), through a focus on signage as representing and negotiating power relations (Spolsky and Cooper 1991; Scollon and Scollon 2003; Ben-Rafael et al. 2006), and on to approaches that take into consideration multiple ways of meaning-making in what have come to be known as semiotic landscapes (e.g. Jaworski and Thurlow 2010). Studies have dealt with the way in which language signs, in interaction with other semiotic resources, can play a role in organising and regulating space (Leeman and Modan 2009; Jaworski 2014). There has been an increasing focus on ethnographically oriented approaches (Blommaert 2013) with recent work exploring language choice in the LL as a reflection of multilingual repertoire management (Matras et al. 2018).

This paper shows how the mobile application LinguaSnapp can be used for collecting and analysing LL. The following section introduces LinguaSnapp as a tool to explore LL. We then draw on examples from Manchester and Jerusalem to show how LinguaSnapp allows for large-scale data collection, and facilitates an exploration of the complex forms and functions of multilingual signs and inter-relations between signs, people and space. Our contribution also addresses the challenges of using a digital tool for LL research, as pilot employment of LinguaSnapp's analytical descriptors prompts us to reflect on categorisations, offering an opportunity to re-think those in the context of the complex reality of urban multilingualism. We then discuss how LinguaSnapp can be tailored to individual cities and in that way allow local branding, before we introduce LinguaSnapp as a tool for engagement and discuss future directions. Our aim is to show how LinguaSnapp can provide new insights into the distribution of languages on signs, and how it can help forward our understanding of the multilingual city, and help re-shape the study of LL and multilingualism more widely.

\footnotetext{
*Corresponding author: Leonie Elisa Gaiser, University of Manchester, Linguistics and English Language, Manchester, Greater Manchester, UK, E-mail: leonie.gaiser@manchester.ac.uk. https://orcid.org/0000-0002-1058-608X

Yaron Matras: University of Manchester, Linguistics and English Language, Manchester, Greater Manchester, UK, E-mail: yaron.matras@manchester.ac.uk
} 


\section{The LinguaSnapp application}

While early research relied on fieldnotes (Rosenbaum et al. 1977) and analogue cameras to document LL (Spolsky and Cooper 1991), studies from the 1990s onwards have used digital cameras to facilitate the collection of larger quantities of pictures. Researchers have called for the development of methods to facilitate comprehensive surveys of larger areas (Blackwood 2015; Soukup 2016), to allow further exploration of the complex relations between LL and space (Lou 2016). In 2015, the University of Manchester's Multilingual Manchester research unit together with the University's Research IT department developed LinguaSnapp, a smartphone application to record and map LL. LinguaSnapp is the first app that engages researchers and students across universities, schools, voluntary sector organisations and the wider public in documenting LL. The app is publicly available for free download from Apple AppStore and Google Play Store.

LinguaSnapp has three components. Smartphone users can use the mobile app to take photos of signs and insert analytical descriptors (Figures 1 and 2).

For each photographed LL-item, users can add information on language use, content, and context. These analytical descriptors accompany the image alongside automatically generated GPS-coordinates that capture the location coordinates where the photo was taken, as well as the date and time the image was created. After taking an image, the user assigns it a name and is then able to save it or to immediately upload it together with the accompanying information onto the LinguaSnapp online database, LinguaSnapp's second component. Here, the editing interface is accessible to registered users - the Multilingual Manchester research team and other appointed editors (e.g. students and researchers from partner institutions) for moderation. Editors check images for relevance and appropriateness, and analytical data for accuracy, and they may add analytical descriptors and translations to ensure consistency and completeness. Registered researchers and students can download selected image metadata and analytical data to a spreadsheet.

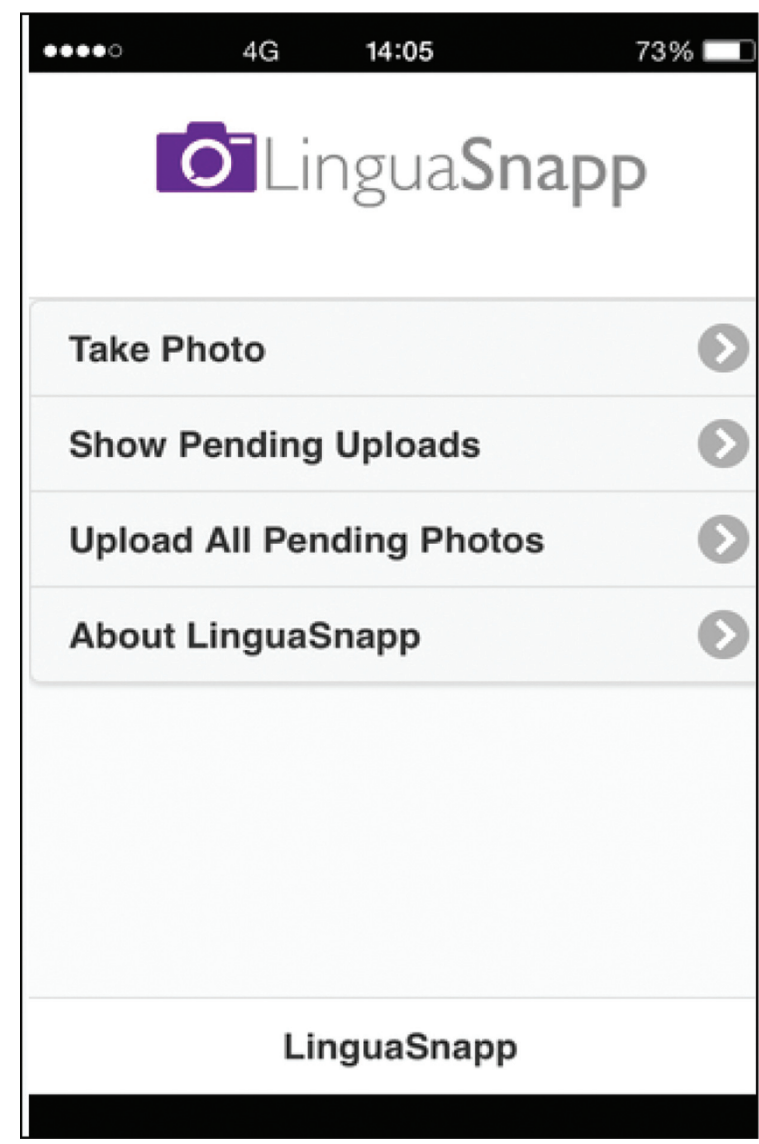

Figure 1: LinguaSnapp app main menu. 


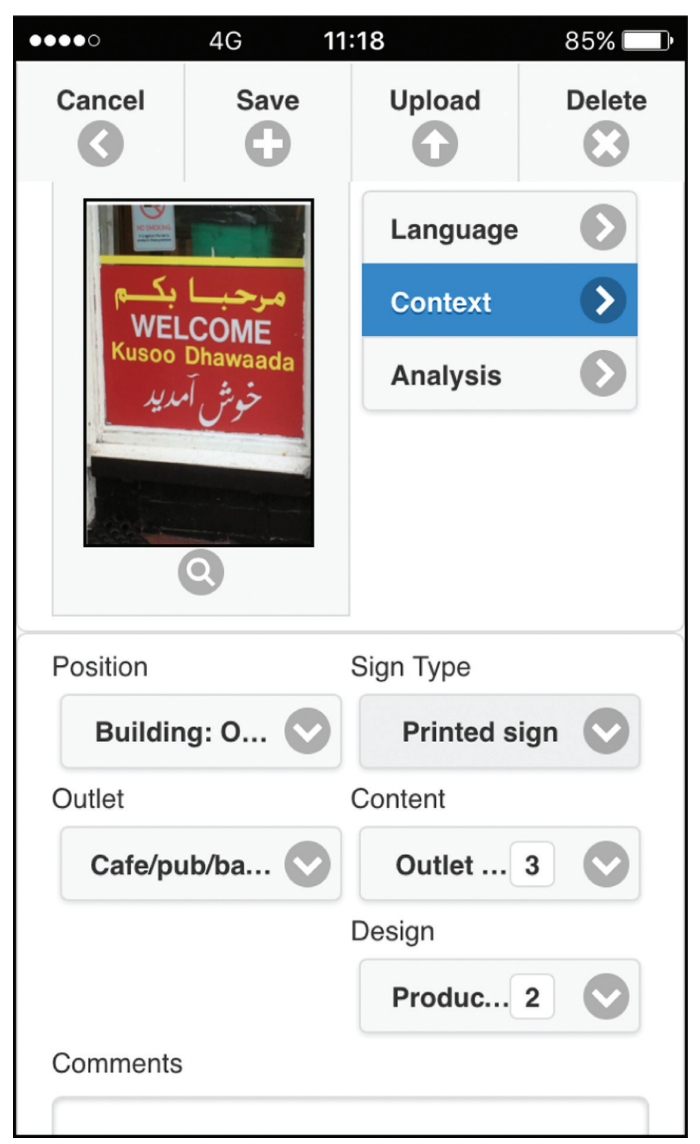

Figure 2: LinguaSnapp app “Context” menu.

LinguaSnapp's third component is the publicly accessible interactive online map, which visualises the geographical distribution of images once they have been approved (Figure 3).

Users can filter searches by selected descriptors. Signs and analytical data can be viewed individually in their geographical location (Figures 4 and 5), or as part of a pattern of spatial distribution of selected features.

LinguaSnapp integrates the Google Streetview function, enabling users to view images in their surrounding landscape.

To meet copyright requirements related to the publication of images, LinguaSnapp users are asked to agree to LinguaSnapp terms and conditions upon registration. Users consent to waiving the copyright over images in favour of The University of Manchester. As LinguaSnapp operates on a non-commercial basis, photographing written texts in the public domain does not (at least in the UK) pose any substantial problems to data collection (UK Copyright, Designs and Patents Act 1988). LinguaSnapp photos must be approved by authorised researchers before they are made publicly visible, ensuring that intellectual property rights are not violated and ethical standards are met, and protecting LinguaSnapp from misuse.

LinguaSnapp's analytical descriptors can be added immediately by using the app on the user's phone or, for registered users, via the editor interface on the online database. The framework is designed to capture the multi-modal complexity of semiotic functions and patterns, combining Reh's (2004) theory of information arrangement with Scollon and Scollon's geosemiotic (2003) and Blommaert's (2013) ethnographic-historical approach. ${ }^{1}$

The category "Language" identifies the number of languages and alphabets, and the languages and alphabets themselves. The user can select options from a menu, or type in a language name in the field "Other". Accompanying the language name is a text field in which a translation can be entered, if necessary,

1 See Gaiser and Matras (2016a) for a full description and illustration of LinguaSnapp’s analytical descriptors. 


\begin{tabular}{|c|c|c|c|c|}
\hline \multirow[t]{2}{*}{ :::: } & \multicolumn{3}{|c|}{ linguasnapp.manchester.ac.uk } & $\star$ \\
\hline & University of ...ester Library $\vee$ dict.cc & Linguee | Deu...re Sprachen) & endnote login & \\
\hline
\end{tabular}

\section{MANCHESTER 1824}

The University of Manchester

Get Tabular Results

Get Mapped Results



\section{a Appstore}



( ) Mobile app information

$0^{-1}$
LinguaSnapp - Manchester's Multilingual

\section{Landscape}

LinguaSnapp is a project to develop a multilingual landscape map of Manchester, UK. We are trying to find the hotspots where more than one language is in common use, and what those languages are. Our app users help us discover this information, by, when walking down the street, reporting any sign, poster, leaflet or other text that is written in more than one language. We are interested in towns and cities from outside Manchester too, in fact anywhere in the world!

This map displays all the photos that have so far been collected by our app users. Browse it using the search boxes on the left hand side.

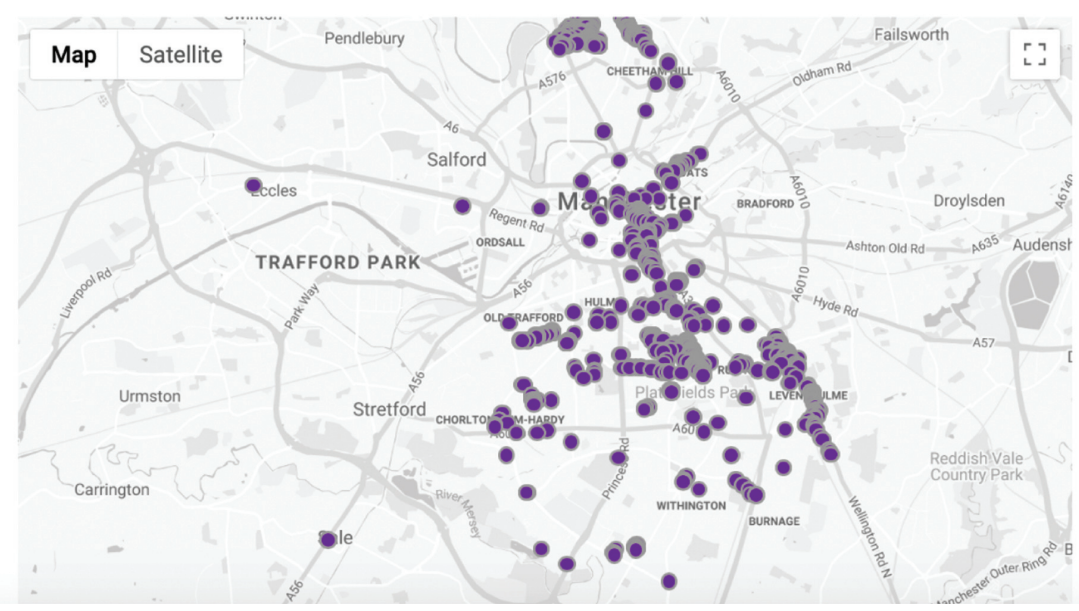

Figure 3: LinguaSnapp interactive map.



Figure 4: Individual photo entry on LinguaSnapp map. 


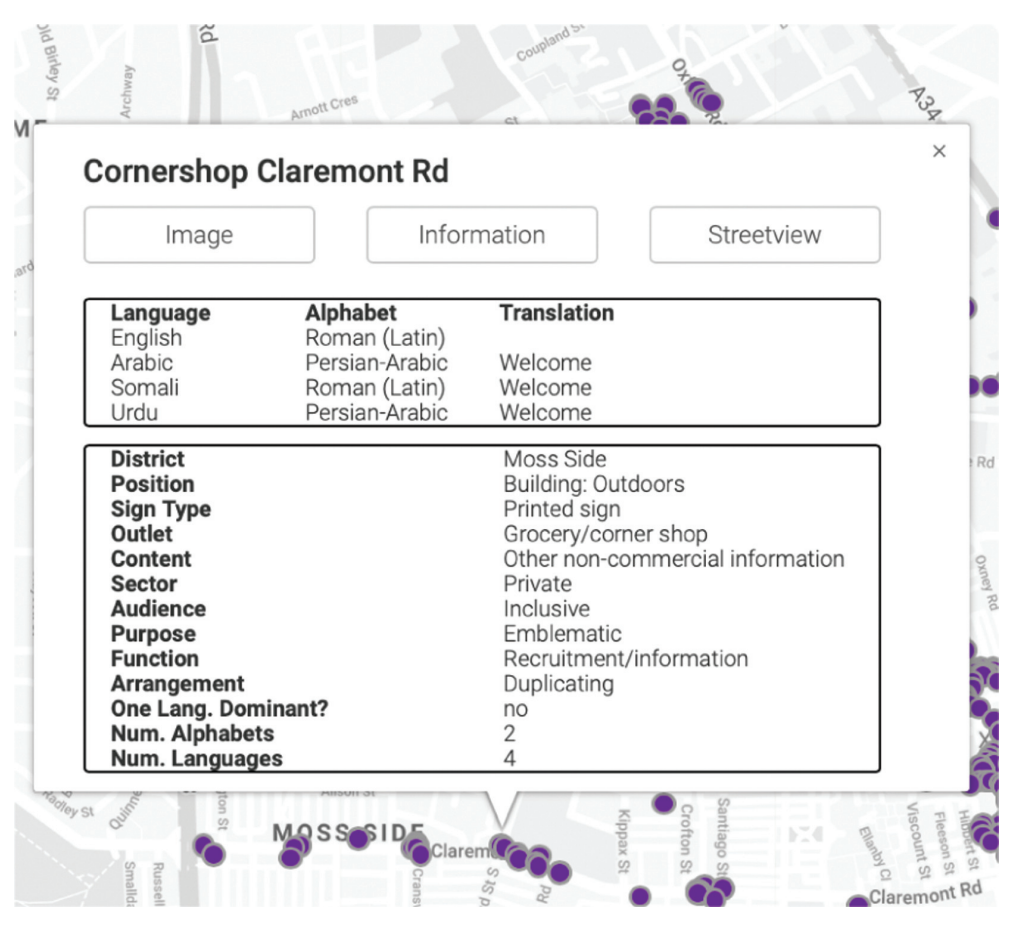

Figure 5: Information for individual photo entry on map.

separately for each language text that appears on the sign. The next category of descriptors targets "Context". The user can identify the Position of the sign (e.g. Building: Outdoors; Building: Indoors; Signpost; etc.) and the Sign Type (e.g. Printed poster; Leaflet; Handwritten note; etc.). The Outlet in which the sign is displayed is identified through a list of options (e.g. Residential; Restaurant; Bakery/butcher; Community centre; Street sign; Public transport vehicle; etc.). This is followed by a general descriptor of the sign's Content, capturing the communicative or informational value of the text (e.g. Outlet name; Product information; Religious/ political message; etc.). Further contextual information addresses visual features (Icon/logo; Product image/ Service image).

The final set of descriptors is referred to as "Analysis"; it captures the distribution and purpose of the sign as well as the relationship among languages. Categories include the Sector of the outlet displaying the message: "Public sector" (top-down) signs are texts authored by or on behalf of government or public agencies and institutions, e.g. traffic signs. "Private sector" (bottom-up) signs are texts authored by businesses and private individuals, ranging from commercial shop signs to handwritten notes. "Voluntary sector" signs are texts put up by non-profit organisations such as religious or cultural institutions. Further Analysis descriptors capture the role of language choice in Audience Selection (exclusive; inclusive), the Language Purpose (communicative; emblematic), the Message Function (recruitment; public statement; etc.), the Language Arrangement (duplicating; fragmentary; overlapping; complementary), and any indication of the Visual Dominance of one language over another on the sign (position; font size; colour; quantity; other).

Most LinguaSnapp descriptors offer a choice of variables; categories can be added during the analysis. In cases where categories are not mutually exclusive, the software allows for multiple selections. A Comments box is used to add any notes that might be relevant for the analysis as well as comments from observations and conversations with local actors.

The complexity of the system of descriptors and its anchoring in the research literature on linguistic landscapes means that LinguaSnapp functions primarily as a tool for individuals with some level of specialised training, rather than as a social enterprise for amateurs. In this regard, it is not a popularisation of so-called "citizen science" but rather a more ambitious endeavour to actually immerse users in the analytical reflections that the categorisations require. Thus, most users so far have been undergraduate and postgraduate students who have received training on how to use the app as part of taught courses at the universities of 
Manchester, Melbourne, St Petersburg and Hamburg, or researchers. However, programmes have also been carried out to introduce the app to school children as part of targeted outreach sessions, where pupils work together with researchers to collect and annotate data. While users need to register, giving the site administrators access to user numbers and an ability to identify contributions by individual users, as a matter of principle LinguaSnapp does not track contributors, and does not collect any personal data on users with the exception of voluntary subscription via email to a mailing list. Nor have we found it purposeful to advertise publicly the number of images uploaded either by individual users, or for individual locations, or for the resource as a whole. A visual impression of the number of images can be gained from a look at the individual LinguaSnapp maps online; at the time of writing this averages between 2000 and 3000 authorised images for the principal research sites so far (Manchester, Jerusalem, Melbourne, Hamburg and St Petersburg). They were collected for each of the locations by around 100 contributors so far, mainly students, while for Jerusalem fieldwork was carried out by the MLM team of researchers.

\section{Assessing the spatial construction of civic identities}

In this section we show how LinguaSnapp and its interactive map are effective tools for identifying language clusters and spatial demarcations across sectors, as well as networking practices that transcend space.

\subsection{Spatial clustering and distribution of languages}

Jerusalem is a multilingual city, as well as a linguistically divided city, where Arabic can be considered to be the majority or dominant language in the East, and Hebrew the dominant language in the West. Both languages have official status, while English is widely used both in the commercial sector and in signs that provide geographical orientation and information on key public services such as transport and emergency services. Figures 6-8 reproduce LinguaSnapp maps for the distribution of Arabic and Hebrew on signs. ${ }^{2}$

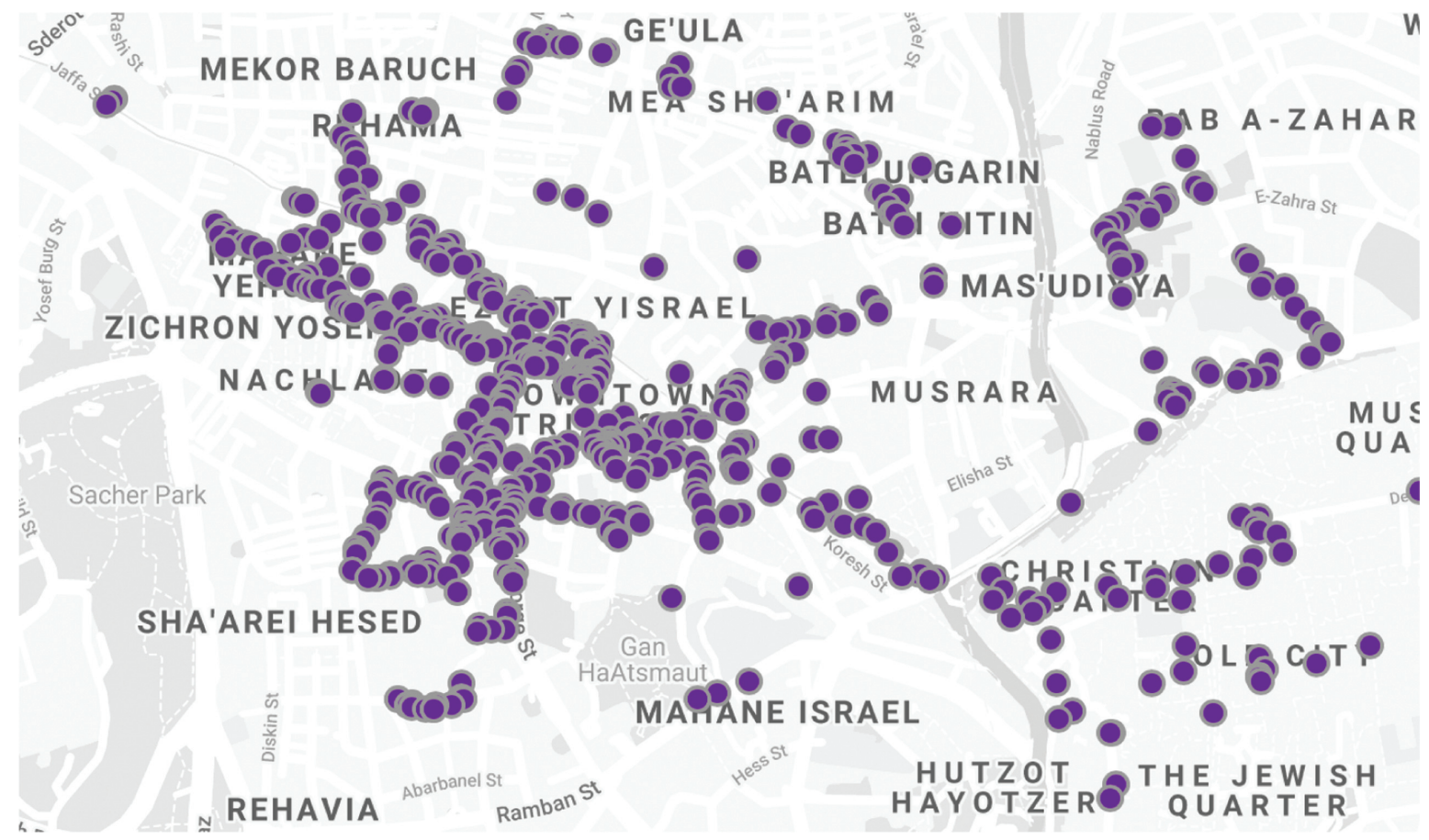

Figure 6: Distribution of Hebrew in Jerusalem's LL.

2 From LinguaSnapp Jerusalem: http://www.linguasnappjlem.manchester.ac.uk. 


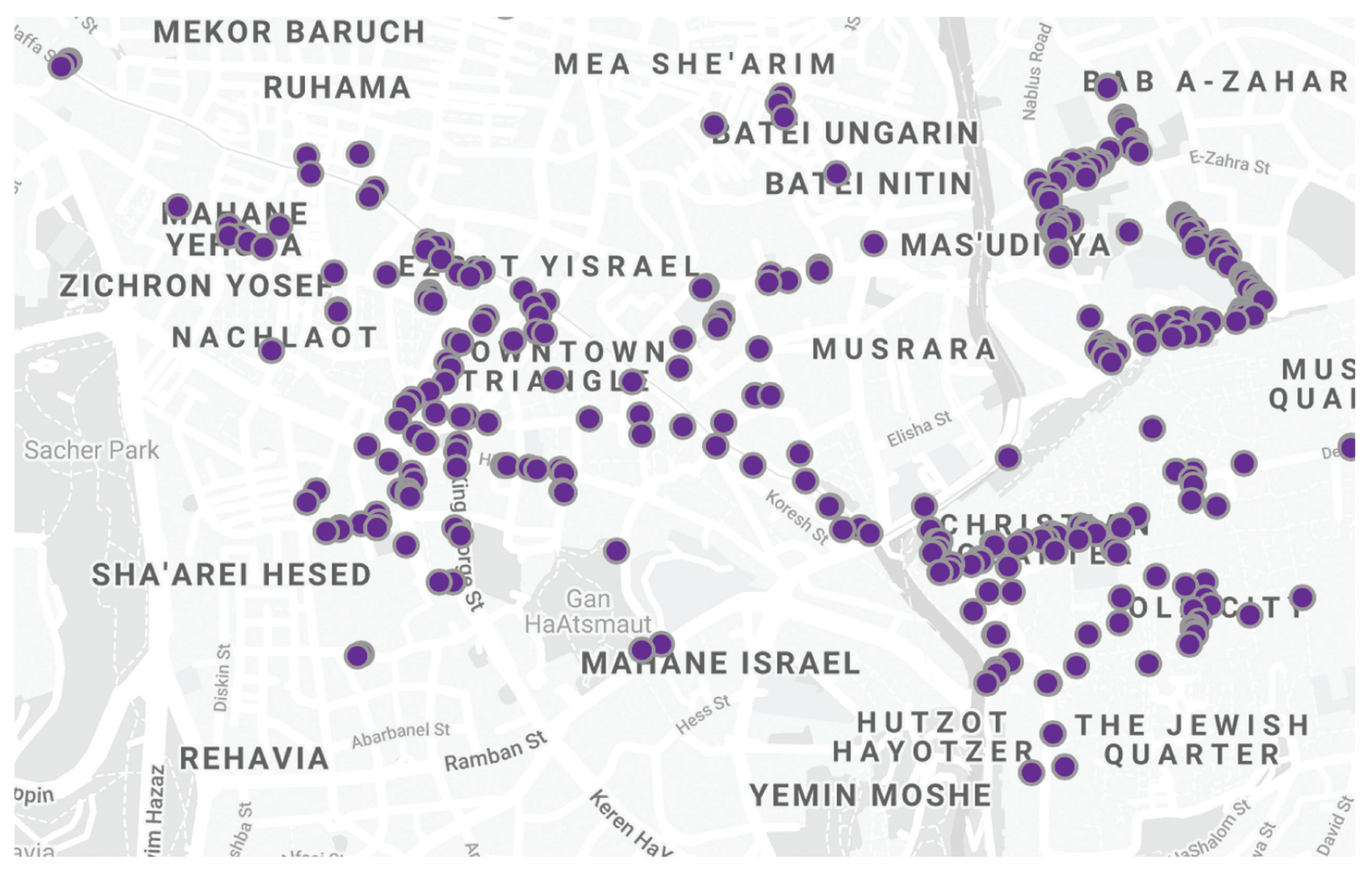

Figure 7: Distribution of Arabic in Jerusalem's LL.

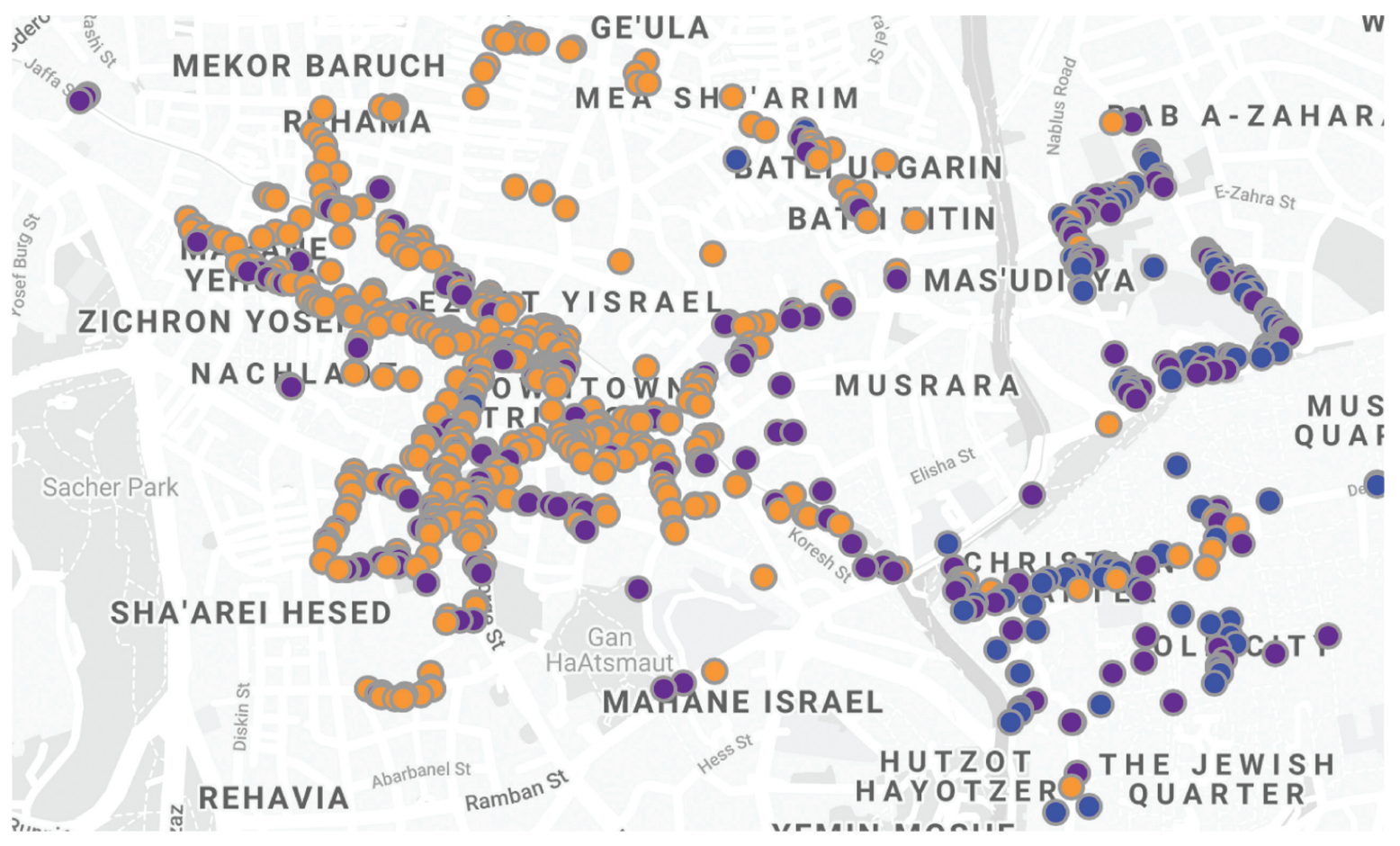

Figure 8: Distribution of Hebrew and Arabic in Jerusalem's LL; orange: Hebrew + potentially additional languages other than Arabic; blue: Arabic + potentially additional languages other than Hebrew; purple: Hebrew \& Arabic + potentially additional languages; for full distribution of all documented languages see online map. http://www.linguasnappjlem.manchester.ac.uk.

While both languages are present across the city's LL, the "majority status” of Hebrew in West Jerusalem and of Arabic in East Jerusalem is reflected in the bottom-up LL. In top-down signs, Hebrew and Arabic, and 
Hebrew and English are present across the city's LL, occasionally all integrated into tri-lingual signage (e.g. traffic signs). The use of these languages on public signs can be seen as an official acknowledgment of diverse participation in space. The use of Arabic in West Jerusalem might be seen both as a gesture of inclusion and as a way to ensure access. English is present on bottom-up signs in both East and West Jerusalem.

For Manchester, we have shown previously how the co-presence and juxtaposition of languages in the LL sub-divides neighbourhoods at the symbolic level (Gaiser and Matras 2016a). For example, the distribution and clustering of language signs along one particular street in North Manchester organises space into contrasting commercial zones, with Urdu dominating in a southern sector and Polish to the north (Gaiser and Matras 2016a: 57f.). The LL demarcates the areas frequented by different communities and maintains symbolic boundaries of "spatial practices" (Lefebvre 1991).

One of the world's first industrial cities, Manchester's social fabric has been shaped by immigration since the mid-19th century. The city has continued to attract new generations of immigrants and is now home to some 200 languages (Matras and Robertson 2015), the largest language groups being Urdu/Panjabi, Chinese, Arabic, Polish, Bengali, Somali and Kurdish.

The LinguaSnapp corpus for Manchester is, with over 2,200 images at the time of writing, currently the largest corpus of LL in an individual city that is publicly available, closely followed by the LinguaSnapp sister corpora for Melbourne, Jerusalem, St Petersburg and Hamburg. The collection of images for Manchester features some 50 different languages with more than a dozen scripts. Manchester's LL reflects the prominence of Urdu, Chinese, Arabic, and Polish as the largest community languages. The LinguaSnapp count reflects, of course, only data that were actively collected; but the top languages recorded are also among the

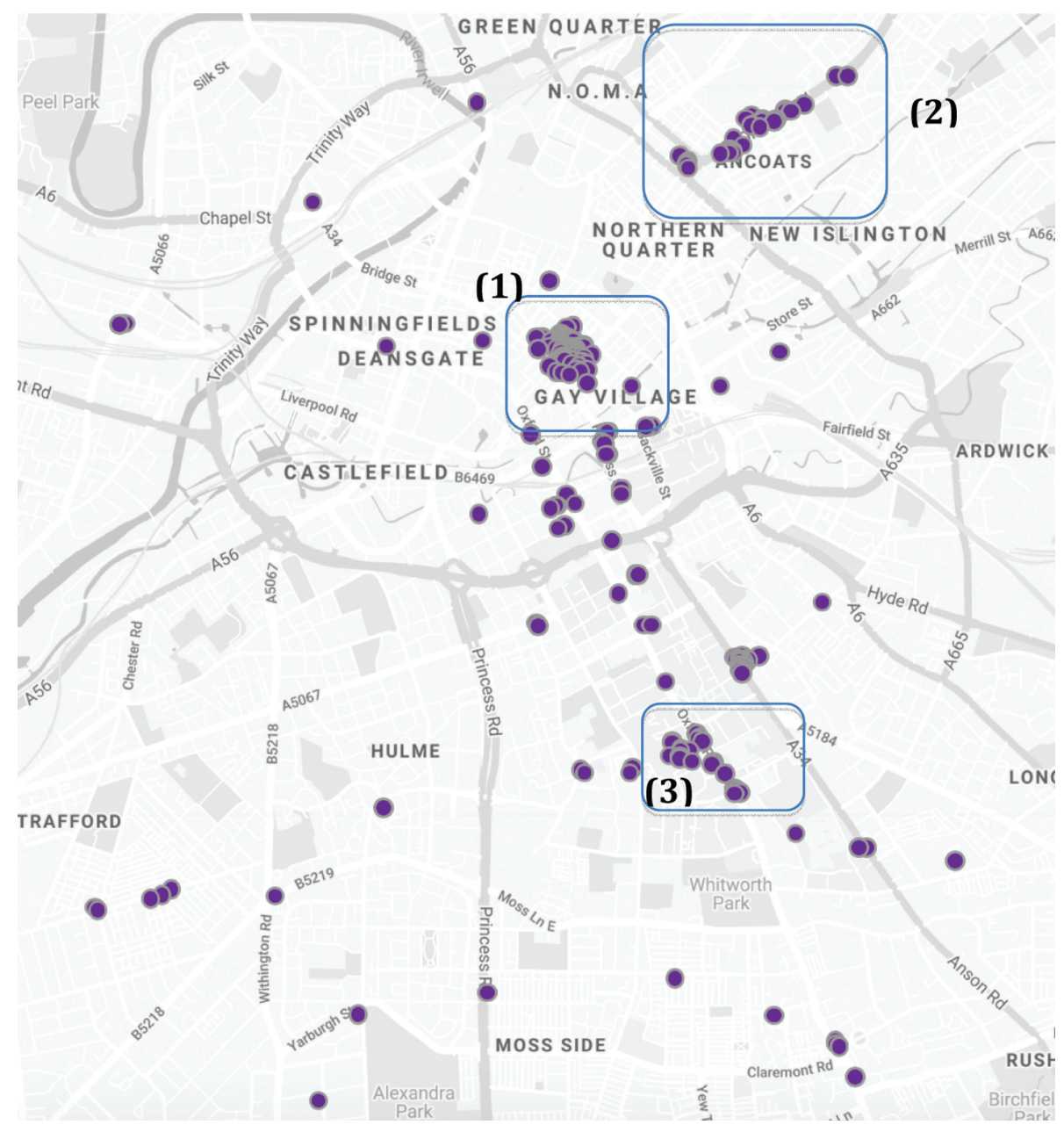

Figure 9: Distribution of Chinese signs in Manchester. 
top languages in the School Census of 2015, the Census of 2011, and the languages requested for interpreter services at Manchester's GP practices (Gaiser and Matras 2016b).

The city's superdiverse character is reflected primarily through private signage. Language choice on private signs, by and large, reflects the residential patterns of Manchester's migrant communities. Furthermore, there is a correlation between language choice and types of business (see Gaiser and Matras 2016a).

Chinese in Manchester's LL is an example of spatial clustering, and at the same time widespread spatial distribution (Figure 9).

Chinese appears as part of a densely concentrated "Chinese space" in the city centre's Chinatown (1), along Oldham Road (2), and around the University (3). These areas are home to, or are frequented by, Chinese speakers who use the language for communication. The public display of the in-group language may be seen as the community's "claim to ownership and legitimate presence and belonging" to the neighbourhoods (Blommaert and Huang 2010: 10).

Additionally, Chinese shows an isolated presence on signage of takeaway outlets scattered across the city. Here, patterns of language use suggest emblematic purposes rather than a need to convey information or content (Figure 10). Typically, English is used for communicative content, and Chinese characters merely offer translations of the outlet names. Exploiting the association of Chinese language with authentic Chinese food, Chinese characters are oriented towards wider audiences as a brand that is recognised across language communities.

Hebrew is tightly concentrated in the LL of some neighbourhoods in North Manchester (Figure 11). It differs from the clustering of Chinese in that it is used in the public space primarily for emblematic purposes.

The signs are oriented towards community values and show no outwards-reaching focus. Hebrew is normally connected with religious contexts, used on façades and inside synagogues and Jewish educational institutions. This ceremonial use is replicated in private domains: Hebrew appears on signs of Jewish-owned businesses serving the community (see Gaiser and Matras 2016a: 82f.). Symbolic use of Hebrew in Manchester's LL can be found also in neighbouring residential areas, where private homes show Hebrew/Yiddish nameplates on their doors (Figures 12 and 13). The signs do not serve any communicative function, as indicated by the consistent use of English for any information relevant to out-group audiences, such as the notice "no free newspapers" (Figure 13).

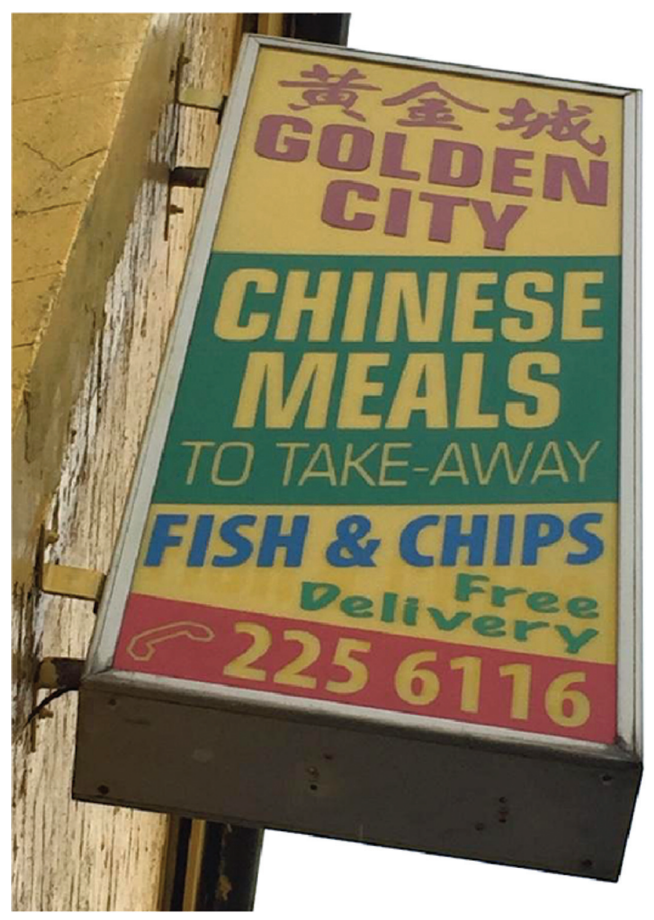

Figure 10: Chinese takeaway sign (“Golden city”). 




Figure 11: Distribution of Hebrew signs in Manchester.

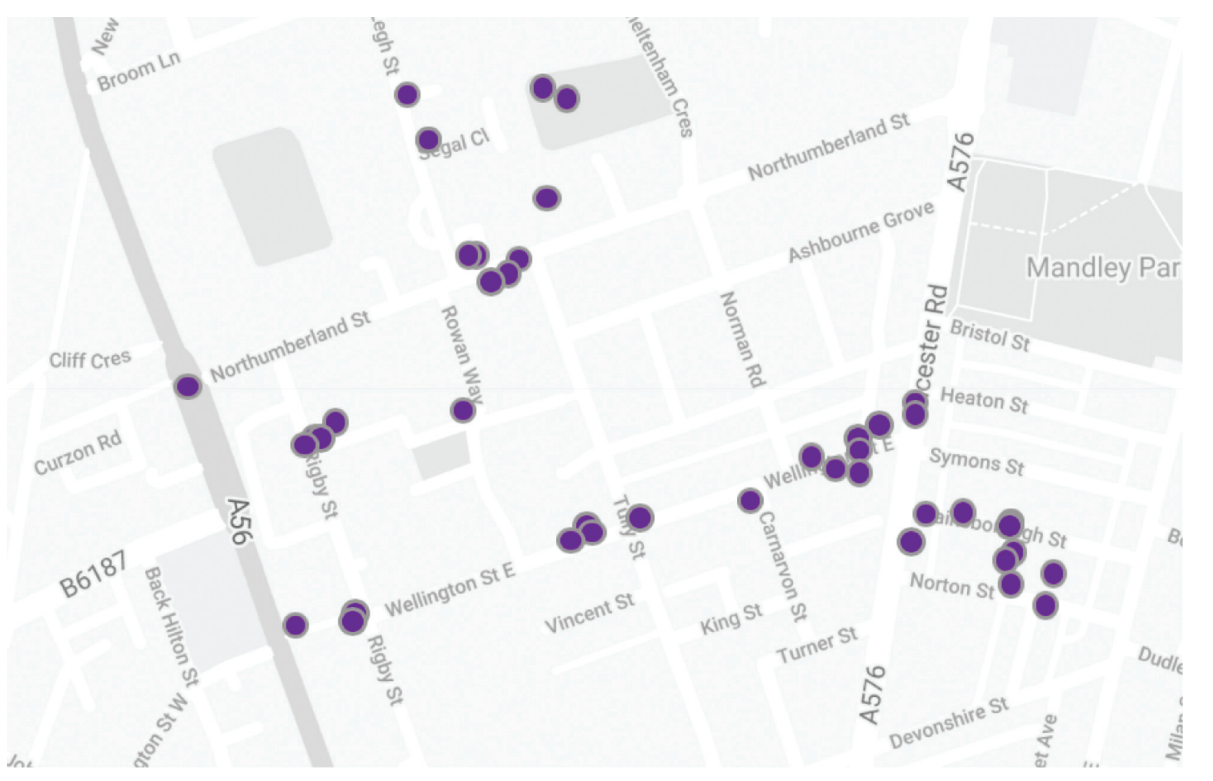

Figure 12: Distribution of Hebrew name signs in North Manchester.

While Hebrew does not serve any informational purpose on these signs, ${ }^{3}$ it expresses the LL-actors' affiliation with their Jewish heritage and reinforces a sense of community identity. This collective assertion of identity through language use has a demarcating effect and serves to claim ownership of space.

3 Inside community institutions, both Hebrew and Yiddish take on communicative functions (see Gaiser and Matras 2016a; Matras et al. 2018). 




Figure 13: Hebrew name signs on private doors in North Manchester.

\subsection{Networks that transcend place}

Another way of organising space through LL-signs is the construction and promotion of social networks. Individuals put up signs in different outlets in the neighbourhood, inter-connecting these places. A Pakistani mortgage company posted their English-Urdu sign in several, also Pakistani-owned outlets in a South Manchester neighbourhood. The poster (Figure 14) addresses the "Pakistani community" through the visually prominent use of Urdu, but English rather than Urdu serves for communication.

The Urdu text is a transliteration of the English word mortgage. Unless readers understand English, they will not be able to access any detailed information about the services. The Urdu script serves emblematic functions: it situates sign authors in relation to passers-by, and singles out Pakistani readers, creating an ingroup discourse. In the distribution of the poster, sign-writers targeted places that use Urdu on their signage, thus remaining within and promoting existing community circles as well as recognised spatial boundaries. In this way, the posters create and reinforce a spatial network of communication. In an interview, the sign owner reported that he was not, in fact, a speaker of Urdu, but relied on a family relation to obtain the transliteration, and that his motivation for doing so was to flag "authenticity" (as someone of South Asian background) in order to gain the trust of potential customers.

Spatial networks can also be established across neighbourhoods. Examples are Russian "lamppost notices" (Figure 15) across Jerusalem (Figure 16). 


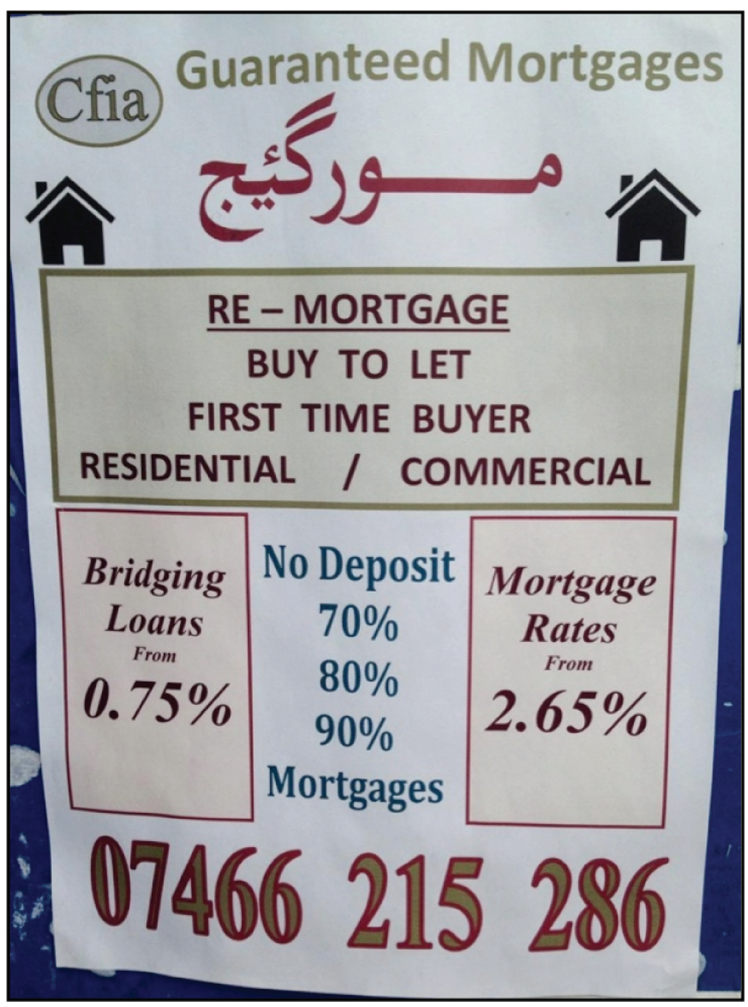

Figure 14: English-Urdu poster in Manchester (“mortgage”).



Figure 15: Russian lamppost notices in Jerusalem (“Association 'kind people' invites for a series of practical exercises 'high music', key to gain physical and mental health. Free entry").

These notices are generally put up by actors who came to Jerusalem as part of a wave of Russian immigration since the early 1990s. Their distribution across various places creates a "lamppost network", which signals actors' participation in a network-based community of practice that is not tied to a specific location of stable outlets but has nevertheless become part of the landscape of the city. Such networks of inter-connected 




Figure 16: Distribution of Russian lamppost notices in Jerusalem.

signs, distributed across recognised spatial units, creates a collectivity effect that relies on mobility routines and social contacts rather than on physical clustering.

\section{Using digital tools for LL research: opportunities and challenges}

We have shown how LinguaSnapp can facilitate systematic, large-scale collection and analysis of LL-images. Our analyses benefit from the availability of the digital tool to assess location, distribution frequency, and co-occurrence of features. LinguaSnapp's combination of imagery, geo-location, link to on-site street-view, and searchable index of descriptors make it a dynamic resource that is suitable for capturing the complexity of publicly written language and the web of interactions that it represents. The application and its interactive map facilitate the identification and geographical distribution of languages in the LL, helping to identify clusters and outliers.

LinguaSnapp's originality and innovation lie in its reliance on analytical descriptors. The app allows users to collect and work with LL data in a way that facilitates a combination of quantitative and qualitative methods in LL research (see Gaiser and Matras 2016a). LinguaSnapp's analytical descriptors allow users to focus on selected features - of individual signs or across signs - in a systematic way.

LinguaSnapp is also the first crowd-sourcing device used to investigate LL. Engaging members of the public in collecting data and sharing data with other researchers reduces the "dependence on the researchers' 
own pictures" (Pavlenko 2010: 133), also allowing the mapping of LL to extend beyond pre-determined survey areas. Including "ordinary" sign readers in documenting the LL allows for the possibility to discover unexpected correlations and outliers. This lessens the impact of subjectivity in data collection and goes at least a step toward mitigating the researcher's perspective on data (Blommaert 2012). LinguaSnapp's public accessibility and use of the familiar Google Maps platform equip it for popular engagement, mirroring the bottom-up and organic nature of LL. Furthermore, LinguaSnapp has the potential to serve as an instrument for surveying commercial and marketing trends as well as for policy planning. Soon after the release of the Manchester version, the resource was listed on Manchester City Council's online Statistics and Intelligence Hub, indicating that it filled a gap in the need for innovative tools to assess the complexity of urban superdiversity.

Using a mobile application for LL research also poses some challenges. First, large datasets such as the LinguaSnapp corpus, with contributions from various users with different levels of experience and training, require close monitoring. Logistical impediments and ethical questions need to be addressed for an effective and exhaustive survey of LL, including the very scale of the task, and the need to obtain access and permission. The research team continuously works to ensure consistency in analysis, completeness of analytical descriptors, and ethical scrutiny. This is done by ensuring that images of individuals (faces) and car registration numbers do not find their way into authorised images (by instructing contributors accordingly, and by refraining to authorise such images in the event that they are uploaded to approval), and asking for permission before taking pictures indoors (in outlets such as shops or cultural institutions). To date, only a few such problematic issues have been encountered, however.

Second, through its dependency on discrete units, the digital tool provokes users into reconsidering the very notion of categories and boundaries. The notion of identifying and counting written "languages" presupposes that these are definable as concrete, enumerable entities. In the individual's mind, linguistic repertoires do not consist of bounded systems but are highly complex (Matras 2009; see also García and Li Wei 2014 on translanguaging, Otsuji and Pennycook 2010 on metrolingualism). Multilingual LL are an indication that the cognitive and social resourcefulness that is behind the deployment of items from the integrated, complex repertoire of structures can also extend to the highly scripted and seemingly regulated mode of writing. In the context of the globalised city, the permeability of language boundaries and residents' holistic appreciation of their language repertoires find their expression in the LL, as users' creative compositions may result in ambiguity of language choice (Gaiser and Matras 2016a). The apparent pitfalls of the need to take decisions on categorisation prove to be an analytical advantage in LinguaSnapp: The digital approach puts a spotlight on the limitations of categorisations that frame multilingual repertoires as inevitable combinations of discrete "languages". LinguaSnapp allows us to identify boundaries and break them down in the analysis. The extensive range of analytic descriptors, the high level of granularity, and the possibility of adding variables help us to avoid simplification. Allowing for multiple selections flags the possibility of multiple category membership and the fuzziness of boundaries.

Finally, it is important to emphasise that the smartphone app is intended as a tool for data collection and archiving, rather than as a research method. The app and administration site facilitate the collection, coding and storing images in a systematic manner, and the interactive map can be used to visualise the distribution and clustering of languages; however, the selection of relevant corpus material and the analysis are obviously carried out by the researcher and not by the software.

LinguaSnapp's range of analytical descriptors and the tool's flexibility can turn these challenges into advantages. LinguaSnapp has the potential to trigger a re-thinking of the ways we approach LL in research. Matras et al. (2018) show how LinguaSnapp is a useful tool for qualitative, ethnographically anchored discourse analysis of the use of multilingual repertoires, showing that LL analysis is not just about identifying power relations expressed in the public sphere, but also about new patterns of inter-community interaction and community formation in linguistically diverse settings.

Among the implications of data collection via the app are thus the ability to correlate linguistic data (on choice of language and script, and content), with location, message content and purpose, and (some aspects of) multi-modality, in a systematic way. Theoretically, this has potential implications for a range of topics. First, the need to deal with signs and language choices as discrete entities instigates a reflection on 
language boundaries and issues such as the representation of language through different scripts, connecting to current discussions on "translanguaging" or "metrolingualism". Next, the ability to explore links, for a large scale sample, between co-occurrence of languages and message content (including outlet, arrangement of languages, and so on) opens up new avenues for a new kind of sociolinguistic domain analysis linking multilingual repertoires with domain specialisation and language vitality. And finally, the ability to correlate, drawing on the database, spatial location with language co-occurrence (in conjunction with the functionality of language choices, as addressed above) offers opportunities to re-think notions of "language communities".

\section{LinguaSnapp as engagement tool}

LinguaSnapp adds a crowd-sourcing element to data collection and facilitates effortless compilation of LLcorpora that reach across cities, countries and continents and are collected over time. In this way it offers an effective tool to involve a variety of users in the documentation task and to capture images spontaneously when the opportunity arises. The app has been employed to collect and archive data for research (Gaiser and Matras 2016a; Matras et al. 2018) and for student projects as part of University teaching. Students at The University of Manchester have used LinguaSnapp for comparative studies of LL across neighbourhoods, to explore LL of businesses and the commodification of language on signs, to study the use of multilingual topdown signs, and more. ${ }^{4}$ In collaboration with local schools, we have used the app to engage pupils with the use of online digital tools through the prism of community languages (see Figures 17 and 18).

We are working with local museums to create activities around LL and are using LinguaSnapp to enrich teaching in weekend schools that teach heritage languages.

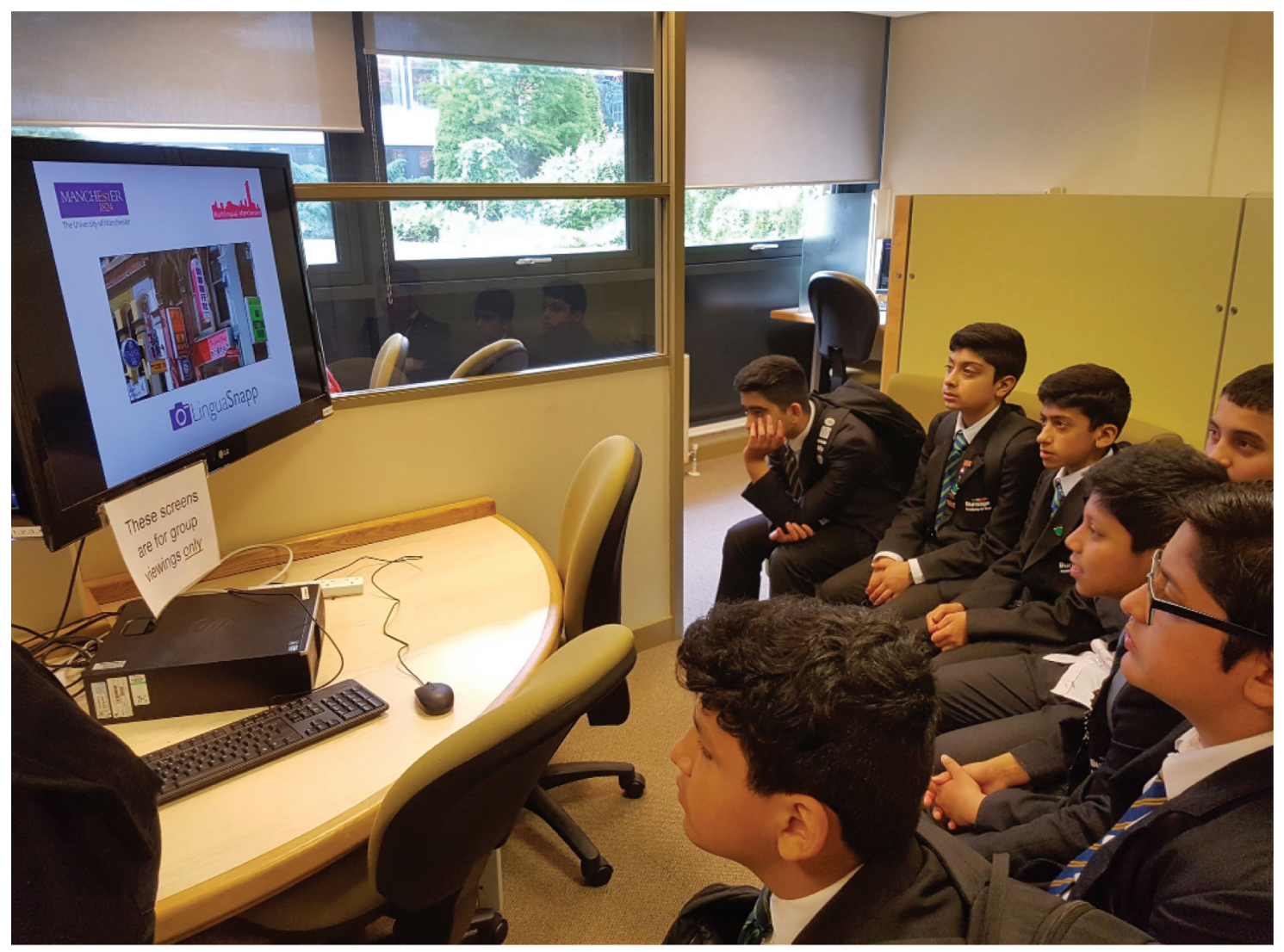

Figure 17: Engaging pupils with LinguaSnapp.

4 For student research using LinguaSnapp see http://mlm.humanities.manchester.ac.uk/reports/linguistic-landscapes/. 


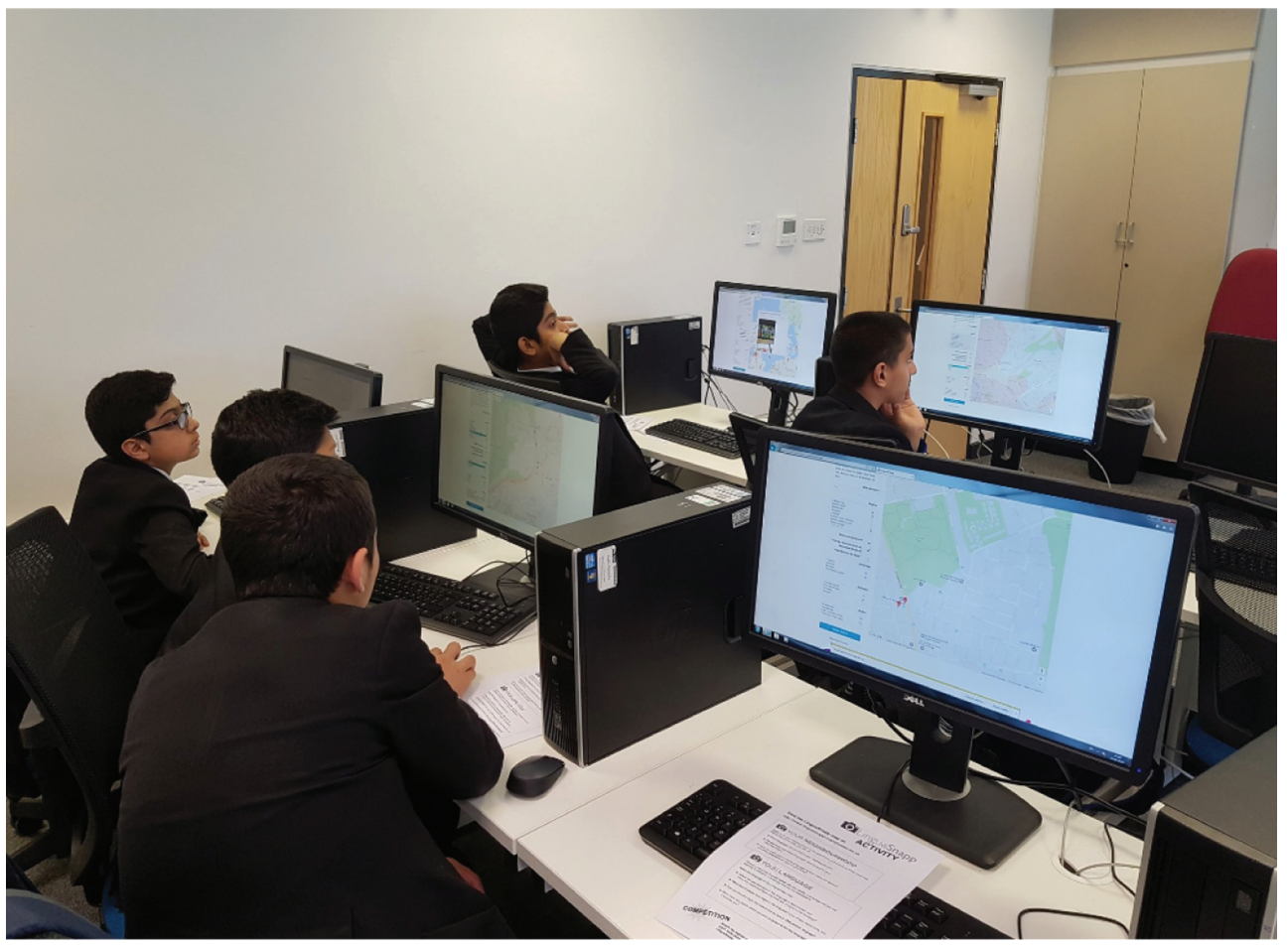

Figure 18: Engaging pupils with the LinguaSnapp online database.

Use of the tool is, of course, not limited to Manchester. The analytical descriptors allow comparison of LL worldwide, comparing corpora in respect of, for example, sector-based, language-based, or design-based trends, and thus to assess local patterns from a genuinely global perspective. Since its launch in Manchester, the application has been adopted and localised by universities in other countries, the first such digital export of the University of Manchester's Humanities Faculty and a model for research, teaching and public engagement in multilingual cities. Versions of LinguaSnapp have been replicated for Jerusalem, Melbourne, St Petersburg and Hamburg, where the tool has been used for research and university teaching. ${ }^{5,6}$ We are currently in negotiations on expanding LinguaSnapp to further cities worldwide. Internationalisation through shared technological innovation can serve as a binding link among cities and researchers.

As a worldwide network of LinguaSnapp researchers and students emerges, the team is working together to develop new features for the application. Under discussion is the development of an API to allow easier immediate access and editing of all corpora; adding "soundscapes" and video material and to feature user interviews related to individual signs; a feature to display historical layering of LL; and integrated combinations with other datasets, such as Multilingual Manchester's data mapping tool.

LinguaSnapp is an example of the ways in which links can be forged between higher education teaching and learning, policy, and public engagement. It serves to raise awareness of language diversity not just through the symbolic act of collecting images, but by offering users an opportunity, and indeed prompting them, to reflect on the purpose and function of multilingual signage and thereby on the way in which language diversity shapes the city's infrastructure, trade, communications, culture and skills. It offers new directions toward an integrated strategy of university public engagement with external stakeholders and fostering internationalisation by linking universities and cities worldwide.

5 For an example of using LinguaSnapp for university teaching see https://lecture2go.uni-hamburg.de/12go/-/get/v/24337.

6 See Baranova and Federova (2020) for an example of research based on LinguaSnapp St. Petersburg. 
Funding: Funder Name: Economic and Social Research Council, Funder Id: http://dx.doi.org// 10.13039501100000269, Grant Number North West Social Science Doctoral Training Partner, Arts and Humanities Research Council (AHRC) Open World Research Initiative consortium "Cross-Language Dynamics: Reshaping Community (Multilingual Communities strand)”, and The British Academy Wolfson Professorial Fellowship, awarded to Professor Yaron Matras.

\section{References}

Backhaus, Peter. 2007. Linguistic landscapes: A comparative study of urban multilingualism in Tokyo. Clevedon: Multilingual Matters.

Baranova, Vlada \& Kapitolina, Federova. 2020. Visible-invisible. Migration and the transformation of St Peterburg's linguistic landscape. Journal of Social Research 12(1). 48-80. [in Russian].

Ben-Rafael, Eliezer, Elana Shohamy, Hasan Amara \& Nira Trumper-Hecht. 2006. Linguistic landscape as symbolic construction of the public space. The case of Israel. International Journal of Multilingualism 31. 7-30.

Blackwood, Robert. 2015. LL explorations and methodological challenges. Linguistic Landscape: An International Journal 1(1/2). 38-53.

Blommaert, Jan. 2012. Chronicles of complexity: Ethnography, superdiversity, and linguistic landscapes. Tilburg Papers in Culture Studies 29.1-149.

Blommaert, Jan. 2013. Ethnography, superdiversity and linguistic landscapes. Chronicles of complexity. Bristol: Multilingual Matters.

Blommaert, Jan \& April Huang. 2010. Semiotic and spatial scope: Towards a materialist semiotics. Working Paper Urban Language and Literacies. https://www.kcl.ac.uk/sspp/departments/education/research/research- centres/ldc/ publications/workingpapers/abstracts/wp062-semiotic-and-spatial- scope-towards-a-materialist-semiotics-janblommaert-.aspx (31 January, 2019).

Gaiser, Leonie \& Yaron Matras. 2016a. The spatial construction of civic identities: A study of Manchester's linguistic landscapes. http://mlm.humanities.manchester.ac.uk/wp-content/uploads/2016/12/ManchesterLinguisticLandscapes.pdf (31 January, 2019).

Gaiser, Leonie \& Yaron Matras. 2016b. Language provisions in access to hospital and primary care in Manchester. Report commissioned by the NHS Clinical Commissioning Groups, Manchester. http://mlm.humanities.manchester.ac.uk/wpcontent/uploads/2016/09/Language-provisions-in-access-to-primary-and-hospital-care-Sept-2016.pdf (31 January, 2019).

García, Ofelia \& Li Wei. 2014. Translanguaging: Language, bilingualism and education. London: Palgrave Macmillan. Jaworski, Adam. 2014. Welcome: Synthetic personalization and commodification of sociability in the linguistic landscape of global tourism. In Bernard Spolsky, Ofra Inbar \& Michal Tannenbaum (eds.), Challenges for language education and policy: Making space for people, 214-231. London: Routledge.

Jaworski, Adam \& Crispin Thurlow. 2010. Semiotic landscapes: Language, image, space. London: Continuum.

Landry, Rodrigue \& Richard Bourhis. 1997. Linguistic landscape and ethnolinguistic vitality. An Empirical study. Journal of Language and Social Psychology 16(1). 23-49.

Leeman, Jennifer \& Gabriella Modan. 2009. Commodified language in Chinatown. A contextualized approach to linguistic landscape. Journal of Sociolinguistics 13(3). 332-362.

Lefebvre, Henri. 1991. The production of space. Blackwell: Oxford.

Lou, Jia. 2016. The Linguistic Landscape of Chinatown: A sociolinguistic ethnography. Bristol: Multilingual Matters.

Matras, Yaron. 2009. Language contact. Cambridge: Cambridge University Press.

Matras, Yaron \& Alex Robertson. 2015. Multilingualism in a post-industrial city: Policy and practice in Manchester. Current Issues in Language Planning 16(3). 296-314.

Matras, Yaron, Leonie Gaiser \& Gertrud Reershemius. 2018. Multilingual repertoire management and illocutionary functions in Yiddish signage in Manchester. Journal of Pragmatics 135. 53-70.

Otsuji, Emi \& Alastair Pennycook. 2010. Metrolingualism: Fixity, fluidity and language in flux. International Journal of Multilingualism 7(3). 240-254.

Pavlenko, Aneta. 2010. Linguistic landscape of Kyiv, Ukraine: A diachronic study. In Elana Shohamy, Elizier Ben-Rafael \& Monica Barni (eds.), Linguistic Landscape in the City, 133-150. Bristol: Multilingual Matters.

Reh, Mechthild. 2004. Multilingual writing. A reader-orientated typology. International Journal of the Sociology of Language 170. 1-41.

Rosenbaum, Yehudit, Elizabeth Nadel, Robert L. Cooper \& Joshua A. Fishman. 1977. English on Keren Kayemet Street. In J. Fishman, R. Cooper \& A. Conrad (eds.), The spread of English, 179-196. Rowley: Newbury House.

Scollon, Ron \& Suzie Wong Scollon. 2003. Discourses in place: Language in the material World. London: Routledge. 
Soukup, Barbara. 2016. English in the linguistic landscape of Vienna, Austria (ELLViA): Outline, rationale, and methodology of a large-scale empirical project on language choice on public signs from the perspective of sign-readers. Vienna English Working Papers. https://anglistik.univie.ac.at/fileadmin/user_upload/dep_anglist/Views_25_2016_Soukup_final_3.pdf (31 January, 2019).

Spolsky, Bernard \& Robert Cooper. 1991. The languages of Jerusalem. New York: Oxford University Press.

UK Copyright, Designs and Patents Act 1988. The National Archives. http://www.legislation.gov.uk/ukpga/1988/48/section/ 62 (31 January, 2019).

Wenzel, Veronika. 1996. Reklame en tweetaligheid in Brussel: Een empirisch onderzoek naar de spreiding van Nederlandstalige en Franstalig affiches [Advertising and bilingualism in Brussels: An empirical study into the distribution of Dutch and French speaking posters]. In Brusselse thema's 3. 45-74. Brussels: Vrije Universiteit. 